\title{
Announcing the inaugural winners of the Simberloff Award for Outstanding Presentation
}

\author{
Sara E. Kuebbing • Laura A. Meyerson
}

Published online: 22 November 2018

(C) Springer Nature Switzerland AG 2018

We are pleased to announce the inaugural recipients of the Simberloff Award for Outstanding Presentation. Together, the Ecological Society of America's (ESA) Invasion Ecology Section, this journal, and Springer International Publishing, will sponsor this annual award to recognize the contributions of Editor-inChief Daniel Simberloff to the study of nonnative species. The award will be given to two undergraduate or graduate students at ESA's annual meeting who embody Simberloff's creativity, intelligence, and passion for studying and understanding the biology of nonnative organisms. For more information about the award, please see the ESA Invasion Ecology website (http://esa.org/invasion/).

Please join us in congratulating Carmela Buono and Amanda Carr for their outstanding poster (Buono) and oral (Carr) presentations at the 2018 Ecological Society of America's Annual Meeting in New Orleans, LA. We asked Carmela and Amanda to share a little bit about themselves, their research, and their favorite publication authored by Dan Simberloff.

S. E. Kuebbing ( $\square)$

Department of Biological Sciences, University of Pittsburgh, Pittsburgh, PA 15260, USA

e-mail: sara.kuebbing@pitt.edu

L. A. Meyerson

Department of Natural Resources Science, University of

Rhode Island, Kingston, RI 02881, USA

e-mail: lameyerson@uri.edu

\section{Carmela Buono}

Outstanding Presentation Title: Are ecological systems resilient to invasions? A systematic review of ecological response post-invasive species management.

Carmela is currently a Ph.D. student at SUNY Binghamton where she studies how anthropogenic change alters species interactions and ecosystem processes in eastern deciduous forests, as well as how to manage these ecosystems. A primary focus of her work is looking at how often and in what context species removal leads to ecological system recovery through a meta-analytic approach. Using observational and field experiments, she also studies antplant mutualisms and how historic land-use and invasive species impact these important interactions.

Most inspiring Simberloff publication: Positive interactions of nonindigenous species: invasional meltdown? (Simberloff and Von Holle 1999).

"I remember reading Simberloff and Von Holle (1999) for a course, but it was critical in my research interests because it helped me to think beyond the single species approach for invasive ecology and consider how multiple invasive species interact. Today, this thinking inspires much of how I approach species interactions in regard to biological invasions, but also plant-insect mutualisms." 


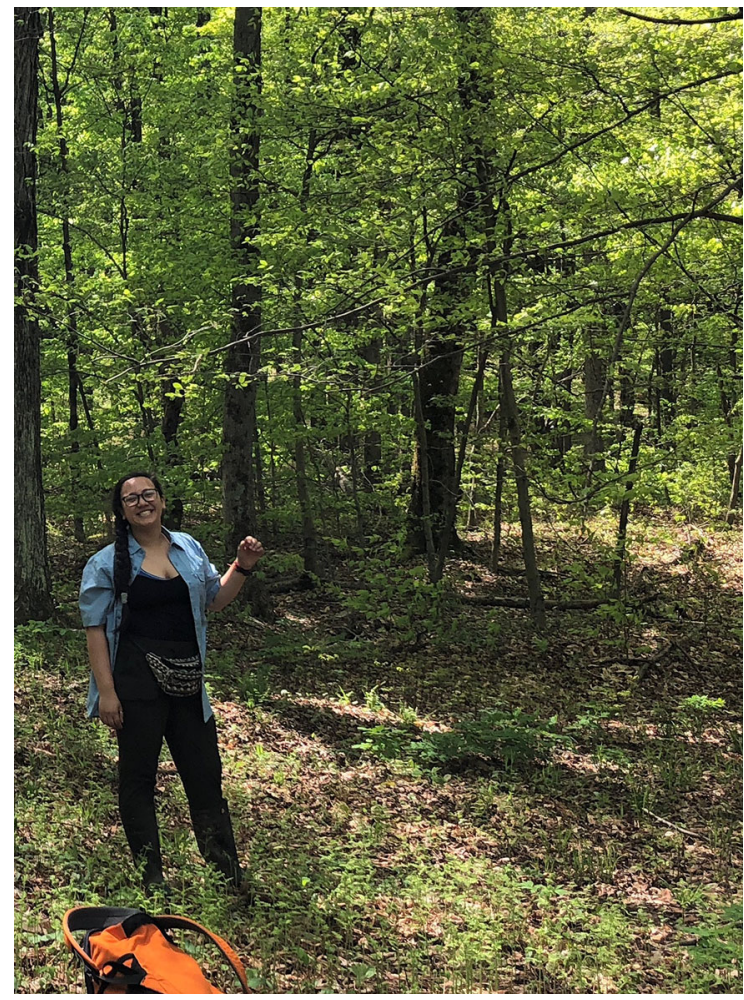

\section{Amanda Carr}

Outstanding Presentation Title: Propagule pressure, not diversity or disturbance, drove long-term invader success in a serpentine grassland.

Amanda graduated in June 2018 with a M.S. degree in Biology from Western Washington University, where she studied the mechanisms of invasion by nonnative plants in California serpentine grasslands. Amanda is interested in understanding why some invasions succeed and others fail, and how mechanisms driving invasions change through time. For her Master's thesis, Amanda addressed these overarching questions using a long-term dataset of experimental plant community assemblages from Santa Clara Valley, California (Carr 2018). Combined with spatially explicit models of seed dispersal, her research suggests that as community assembly progresses, neutral processes like variation in propagule pressure become relatively more important than community composition and diversity in determining the species identity of successful invaders.
Most inspiring Simberloff publication: Ecological Resistance to Biological Invasion Overwhelmed by Propagule Pressure (Von Holle and Simberloff 2005).

In an elegant field experiment, Von Holle and Simberloff (2005) found strong, causal evidence of propagule pressure outweighing both disturbance and community composition as determinants of invader success. To me, this publication represents the gold standard of manipulated ecological experiments, demonstrating empirically what observational studies had previously suggested. This publication also provided a crucial pin in my thesis research, as the results offer strong mechanistic support for my hypothesis of propagule pressure overwhelming community determination of invader success through time.



\section{References}

Carr AN (2018) Long-term propagule pressure overwhelms early community determination of invader success in a serpentine grassland. Thesis, Western Washington University

Simberloff D, Von Holle B (1999) Positive interactions of nonindigenous species: invasional meltdown? Biol Invasions 1:21-32

Von Holle B, Simberloff D (2005) Ecological resistance to biological invasion overwhelmed by propagule pressure. Ecology 86:3212-3218 